\title{
Dominant periods of the 2004 Sumatra tsunami and the estimated source size
}

\author{
Kuniaki Abe \\ Niigata Junior College, Nippon Dental University, Hamauracho 1-8, Niigata 951-8580, Japan \\ (Received July 5, 2005; Revised February 14, 2006; Accepted February 14, 2006; Online published February 17, 2006)
}

\begin{abstract}
Dominant periods determined from tide gauge records of the 2004 Sumatra tsunami were used to estimate the size of the tsunami source. A period of 40 minutes dominates the initial motions and spectra are consistent with a fault width of $110 \mathrm{~km}$ for a sea depth of $1000 \mathrm{~m}$. Another dominant period of 140 minutes in the spectra observed at the direction of fault azimuth can be explained using a fault length of $1200 \mathrm{~km}$. These values taken together are consistent with source formation on the continental slope with width of $110 \mathrm{~km}$ and length of $1200 \mathrm{~km}$ along Nicobar and Andaman Islands.
\end{abstract}

Key words: Dominant period, Sumatra tsunami, tide gauge records.

\section{Introduction}

The 2004 Sumatra tsunami was generated by an earthquake with origin time of $0 \mathrm{~h} 58 \mathrm{~m} 53 \mathrm{~s}$ on 26 December 2004 and moment magnitude 9.0, which has epicenter of $3.316^{\circ} \mathrm{N}, 95.854^{\circ} \mathrm{E}$, focal depth of $30 \mathrm{~km}$ (http://earthquake. usgs.gov/eqcenter/eqinthenews/2004/usslav/). The epicenter is located off the west coast of Sumatra, Indonesia. The tsunami propagated across Indian Ocean and resulted in tremendous damages to Indonesia, Thailand, India, Sri Lanka and Maldive. Many Japanese survey teams visited these countries and collected useful data including maximum trace height (e.g. Tsuji et al., 2005). Among the useful data are tide gauge records. Although the main purpose of the tide stations is to record tidal level, the records are also useful to analyze tsunami, especially at long-periods. After the Sumatra tsunami Fujima (2005) carried out the survey in the Maldives and reported that the observed maximum trace height is similar to that of tide gauge record at Hanimaadhoo. This fact suggests that the period was long enough for the tide station to reproduce the sea level.

Here, we will use tsunami tide gauge records to estimate the source size. Yamashita and Sato (1974) derived the theoretical spectrum of tsunami generated at constant depth sea by a rectangular fault under the sea. In this framework the tsunami is formed through unilateral rupture propagation along the fault. Their results reveal a directivity of amplitude distribution. At the same time they show a directivity of dominant period, which is the period corresponding to maximum spectral amplitude. That is, long period components occupy the maximum amplitude along the strike direction and short ones occupy the maximum amplitude in the direction normal to the fault strike. The dominant periods depends on fault parameters. Comparing the observed dominant periods with the theoretical ones at both directions we can estimate fault parameters as a type of inversion

Copyright (c) The Society of Geomagnetism and Earth, Planetary and Space Sciences (SGEPSS); The Seismological Society of Japan; The Volcanological Society of Japan; The Geodetic Society of Japan; The Japanese Society for Planetary Sciences; TERRAPUB. problem.

A preliminary result estimated using inverse refraction diagram was that the source length was $600 \mathrm{~km}$. On the other hand the aftershock area has a linear dimension longer than $1000 \mathrm{~km}$ (Satake, 2005). One method to find the tsunami source size without using an inverse refraction diagram is to examine the dominant period in the spectra through analysis of the tide gauge records.

\section{Analysis of Tide Gauge Records}

As a preliminary step initial periods of tide gauge records are summarized. The tide stations analyzed are as follows: Vishakapatnam, Tuticorin, Kochin, Marmugao (http://www.nio.org/jsp/tsunami.jsp), Hanimaadhoo, Male, Gan, Diego Garcia, Salalah, Pt La Rue, Lamu, Zanzibar (http://ilikai.soest.hawaii.edu/uhslc/), Showa Base (http:// www1.kaiho.mlit.go.jp/KANKYO/KAIYO/jare/tide/tide_ index.html), Cocos, Jackson Bay, Arica, Callao (http:// wcatwc.arh.noaa.gov/IndianOSite/IndianO12-26-04.htm), Sibolga (Tsuji et al., 2005). These tide stations except for Jackson Bay (New Zeeland), Arica (Chile) and Callao (Peru) are shown in Fig. 1. The tide gauge data were down loaded and all the data were digitized for use in computer calculations. All the time series are used without correction due to the long period dominance. From the records we measured initial periods, those are time intervals of peak to peak in the first upward motions. The example is shown in Fig. 2 and histogram of the initial periods is shown in Fig. 3. The distribution reveals a dominance of 40 minutes in the period. Dominance of periods shorter than the 40 minutes is possibly attributed to a local oscillation in the vicinity of the station. When we select tide stations located at an azimuth between $\mathrm{N} 280^{\circ} \mathrm{E}$ and $\mathrm{N} 197^{\circ} \mathrm{E}$ to the epicenter, which correspond to stations approximately located at a relative azimuth $\phi$ of $270^{\circ}$ as defined in Fig. 1, the average period is 39.4 minutes. This result suggests a dominance of 40 minutes in the spectral components.

The time series were decomposed into amplitude spectra selecting ones of good quality. The tide station of Vishaka- 


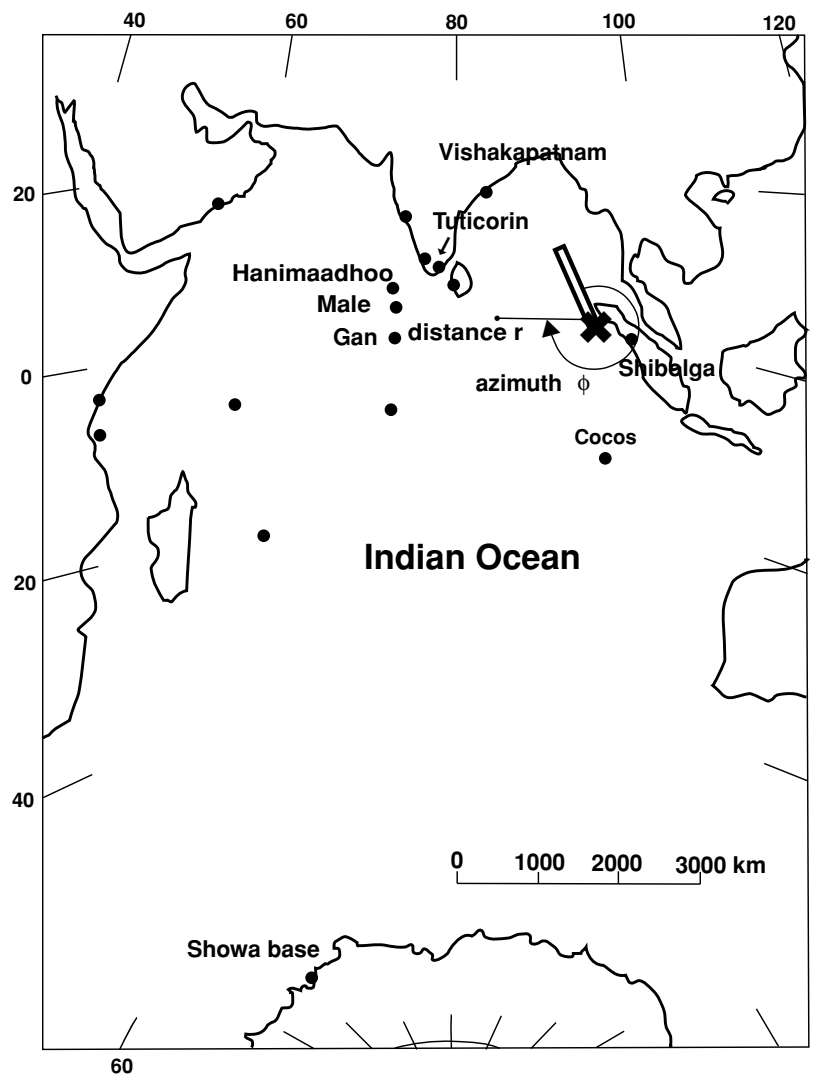

Fig. 1. Tide stations used for spectral analysis and fault source assumed. Cross is epicenter.

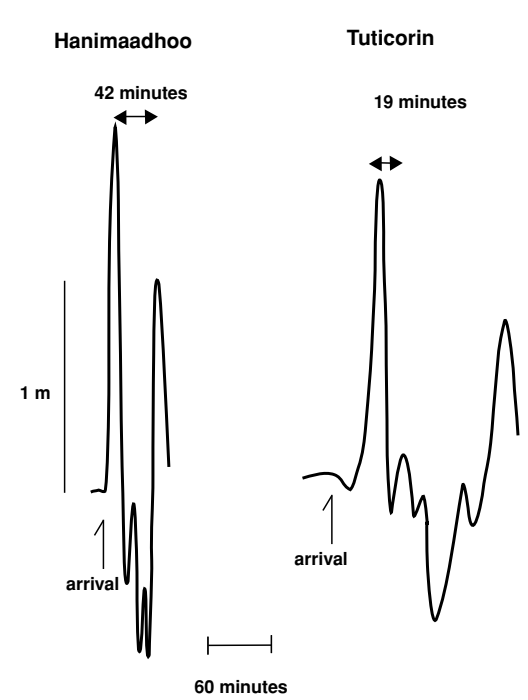

Fig. 2. Examples of reading initial periods.

patnam was of lesser quality but included in the analysis because of its approximate direction along strike. The discontinuous parts of the record were interpolated. A method of spectral analysis was the same as that of Abe (2005). Thus, spectra for eight tide stations were obtained : Vishakapatnam, Tuticorin, Hanimaadhoo, Male, Gan, Showa base, Cocos, Sibolga. Total sampling time in universal time (UT) and the interval in minute are shown in Table 1 with results shown in Fig. 4. In the figure we find many cases of dominance at $40 \mathrm{~min}$. The representative cases are those

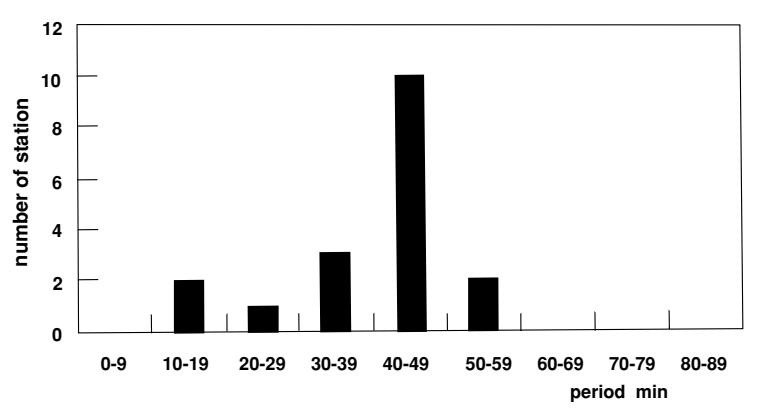

Fig. 3. Classification of initial periods observed at tide stations.
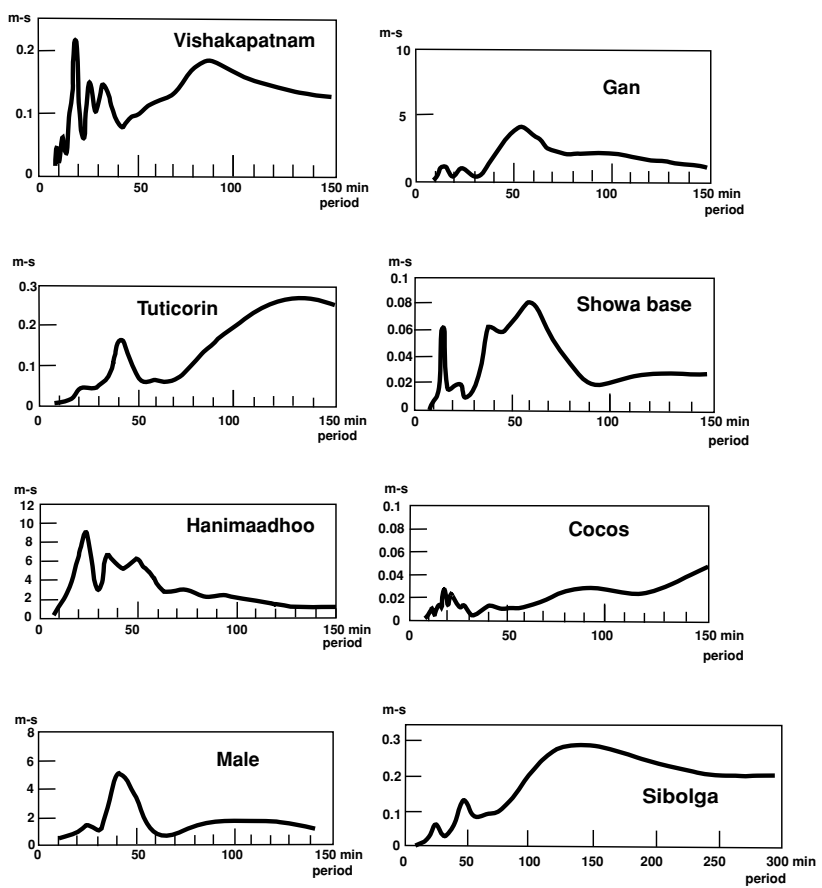

Fig. 4. Amplitude spectra of 2004 Sumatra tsunami.

Table 1. List of tide stations used for spectral analysis. Total sampling times and the time intervals are not same because of differences of original ones.

\begin{tabular}{llcc}
\hline Tide station & Date (UT) & Time (UT) & Time interval (min) \\
\hline Vishakapatnam & Dec. 26 & $3: 00-9: 00$ & 1 \\
Tuticorin & Dec. 26 & $2: 00-8: 00$ & 1 \\
Hanimaadhoo & Dec. 26 & $4: 00-16: 00$ & 2 \\
Male & Dec. 26 & $0: 00-24: 00$ & 4 \\
Gan & Dec. 26 & $0: 00-18: 00$ & 4 \\
Showa base & Dec. 26-27 & $19: 00-1: 00$ & 1 \\
Cocos & Dec. 26 & $3: 00-9: 00$ & 1 \\
Sibolga & Dec. 26 & $2: 00-14: 00$ & 2 \\
\hline
\end{tabular}

of Tuticorin and Male. The data from Hanimaadhoo shows an indirect dominance of $40 \mathrm{~min}$ from the interpretation of splitting into 35 and $49 \mathrm{~min}$. At Showa base a small peak of a $40 \mathrm{~min}$ was observed. At Gan a period of $52 \mathrm{~min}$ is dominant. Thus, many instances of a 40 min dominant period are also revealed in the spectra. Because the total spectrum is a result of summation during the entire record that is sampled and because the dominant period coincides with the initial period, it suggests no excitation of secondary undulation with other period components. It is reasonable that 


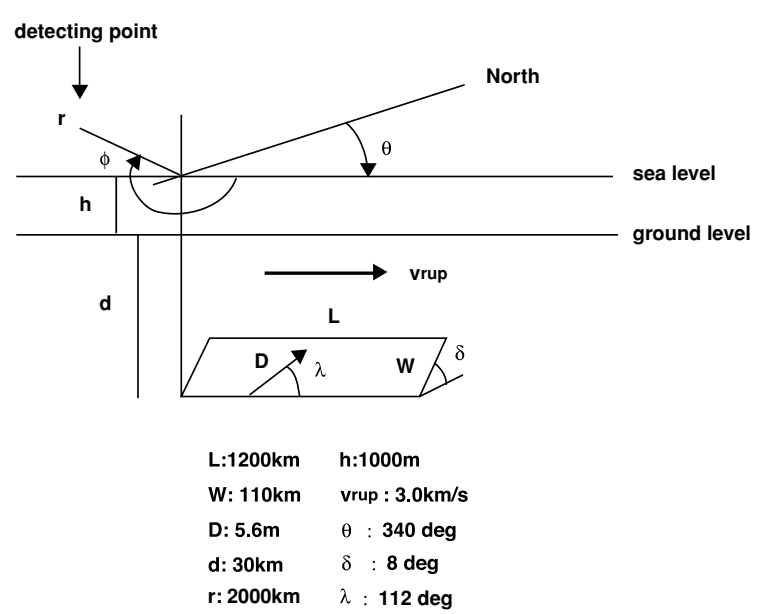

Fig. 5. Definition of fault parameters.

the simple peaks of 40 min observed at Tuticorin and Male reflect the initial condition. To discuss the nature of the source we will use this result as a representative period normal to the direction of the fault.

On the other hand, the spectrum along $\mathrm{t}$ strike direction show a dominance of longer periods. An example is data observed at Sibolga, Indonesia showing a peak in the period of $139 \mathrm{~min}$. The station azimuth is sub-parallel to the strike direction. Dominance of the same period is also found in Tuticorin, which is at a greater azimuth from the strike direction. We will use the period of 139 minutes as a representative period of the strike direction.

\section{Theoretical Model}

We calculated the theoretical spectrum using the formula by Yamashita and Sato (1974). The fault model and the parameters are illustrated as shown in Fig. 5. The spectrum is estimated at a point on the sea having a distance of $r$ from the origin, which is a corner of lower margin of the fault plane. The azimuth $\phi$ is defined relative to the strike direction. Direction of rupture propagation is taken to be positive in the $\mathrm{x}$ direction. In the calculation, the fault mechanism is assumed to be the same as derived by Yamanaka (2005), which consists of a seismic moment of $3.5 \times 10^{22} \mathrm{Nm}$, azimuth angle of $\mathrm{N} 340^{\circ} \mathrm{E}$, dip angle of 8 degrees and slip angle of 112 degrees. This solution is typical of that for an inter-plate thrust fault of low dip-angle. Other parameters needed to estimate the spectrum are taken from the original paper except for rupture velocity $v_{\text {rup }}$. Variable parameters are length $L$, width $W$, fault depth $d$, rupture velocity $v_{\text {rup }}$ and sea depth $h$. Dislocation $D$ depends on seismic moment, length and width. A rigidity of $4.3 \times 10^{10} \mathrm{~N} / \mathrm{m}^{2}$ was assumed to be constant. The criterion to determine the best parameters is that which reproduces the dominant period, defined as the period of the maximum amplitude in the spectrum. In every case the spectrum is estimated at a distance $r$ of $2000 \mathrm{~km}$ and relative azimuths $\phi$ of 180 and $270 \mathrm{de}-$ grees. Neglecting the effect of the sea-land boundary at the tide stations we compare the observed spectra with the theoretical ones. The combination of optimal parameters was determined by trial and error, and the best fit model was selected through a comparison of more than 30 models. The



Fig. 6. Theoretical tsunami spectra. Amplitude is normalized by $D h / v_{s}$, in which $v_{s}$ is $S$-wave velocity.

amplitude is normalized by $h D / v_{s}$ and shown for as a function of period, in which $v_{s}$ is the velocity of $S$ wave. The spectra for relative azimuths of $0,315,270,225$ and 180 degrees are shown in Fig. 6. The best fit model consists of the length $=1200 \mathrm{~km}$, width $=110 \mathrm{~km}$, sea depth $=1000 \mathrm{~m}$, rupture velocity $=3 \mathrm{~km} / \mathrm{s}$ and fault depth $=30 \mathrm{~km}$. As shown in Fig. 6 we can explain the dominant 40 and 139 minutes at azimuths normal and parallel to strike, respectively.

The dominant period of 93 minute observed at Cocos approximately coincides to the 100 minutes theoretical period calculated at a relative azimuth of 225 degrees. Moreover, a dominant period of 83 minutes observed at Vishakapatnam, is approximately equal to the 90 minutes theoretical period at a relative azimuth of 315 degrees.

The tsunami source was estimated to occur on the continental slope in front of Nicobar and Andaman Islands by Satake (2005). The sea depth there approximately varies from 4000 to $0 \mathrm{~m}$ on the slope. Assuming a constant slope from $4000 \mathrm{~m}$ to $0 \mathrm{~m}$ in the sea depth and calculating the travel time of tsunami across the slope, we obtain the average velocity of $99 \mathrm{~m} / \mathrm{s}$ for a sea depth of $1000 \mathrm{~m}$. This consideration gives us a physical meaning of the sea depth of $1000 \mathrm{~m}$ obtained in the former section. At the same time the width of $110 \mathrm{~km}$ is found to be approximately same the horizontal dimension of the slope. This is consistent with the source covering all the sloping area.

\section{Parameter Dependence of Dominant Period}

Parameter dependence of the dominant period is indicated by the results shown in Figs. 7-9. In these calculations one parameter is variable and others are held constant 

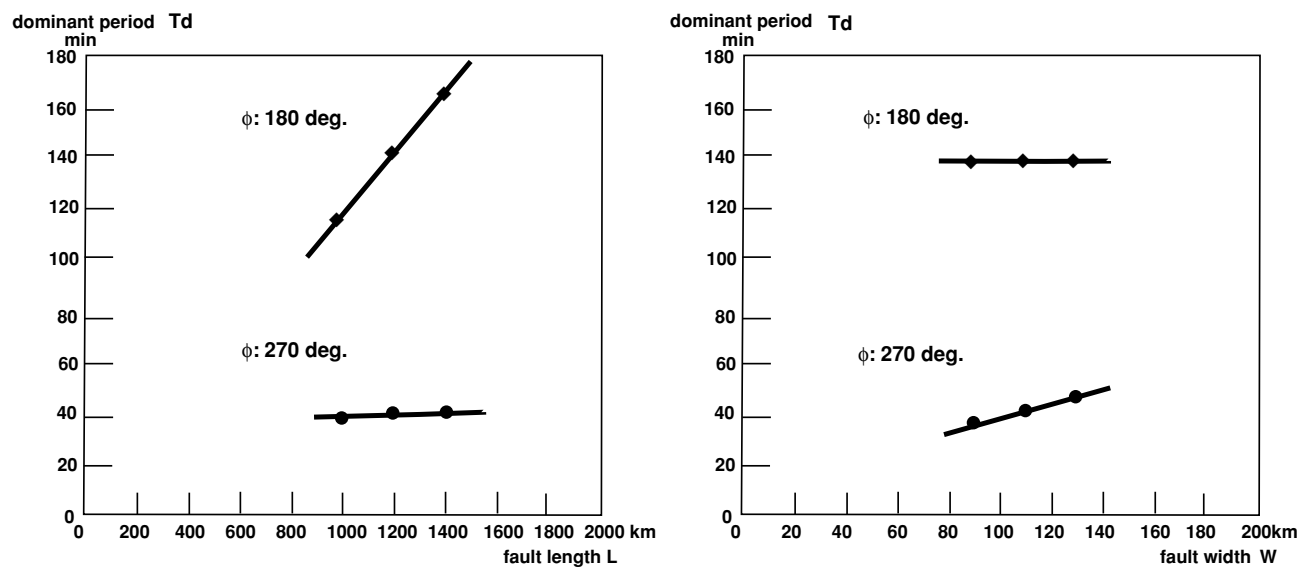

Fig. 7. Dependences of dominant period on fault length $L$ (Top) and width $W$ (Bottom). Other fault parameters are fixed same as ones of the best one.
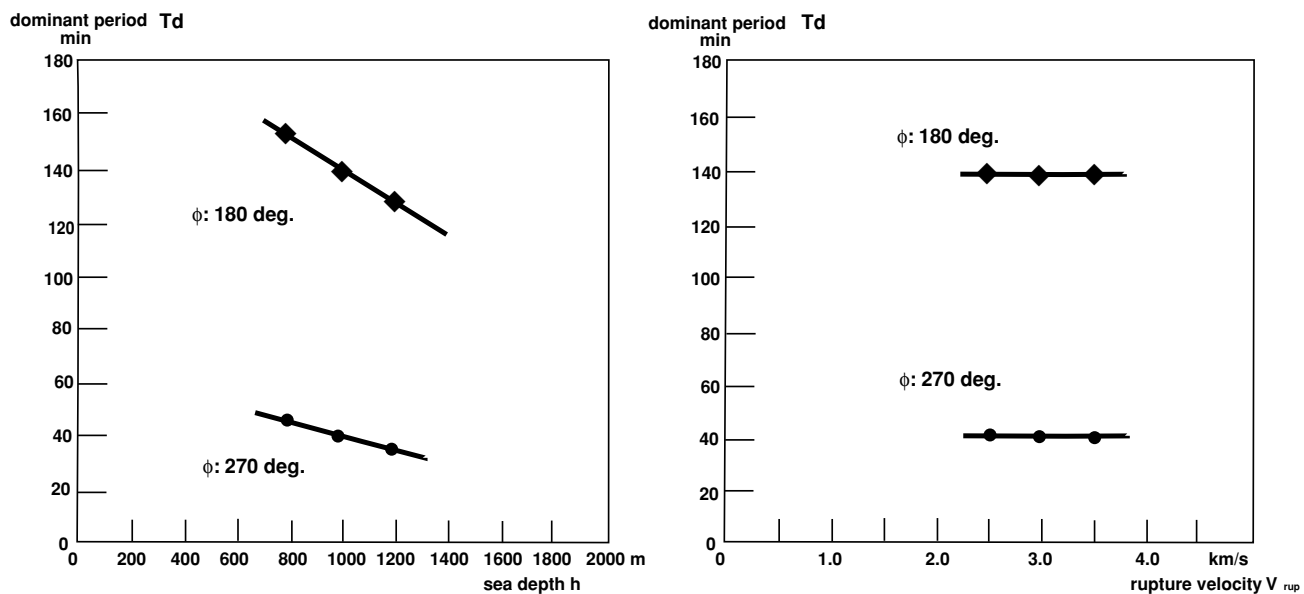

Fig. 8. Dependences of dominant period on sea depth $h$ (Top) and rupture velocity $v_{\text {rup }}$ (Bottom). Other fault parameters are fixed same as ones of the best one.

to values determined for the best fit model. The calculations were determined for two positions $2000 \mathrm{~km}$ distant from the lower margin and at relative azimuths of 270 and 180 degrees. These points and one for the best fit model are shown in each case. The right point corresponds to an increase and the left one do to a decrease. The slope represents variation of the dominant period with an increase in the parameter. The horizontal line indicates no variation and the solution is locally stable. From this result it is understood that the length and width give large effects to the dominant periods at azimuth angles of 180 and 270 degrees, respectively (Fig. 7). Sea depth can cause a variation of the dominant period for both the directions (Top of Fig. 8). On the other hand fault depth results in a small effect to the dominant period at the direction of 270 degrees (Fig. 9). Effect of rupture velocity to the dominant period is small (Fig. 8). Thus, it is concluded that length, width and sea depth are the critical parameters that determines the dominant periods of tsunami.

\section{Discussion}

It is interesting to discuss the relation between wave length of a tsunami and fault size. In the direction of fault strike, wave length corresponding to the dominant period

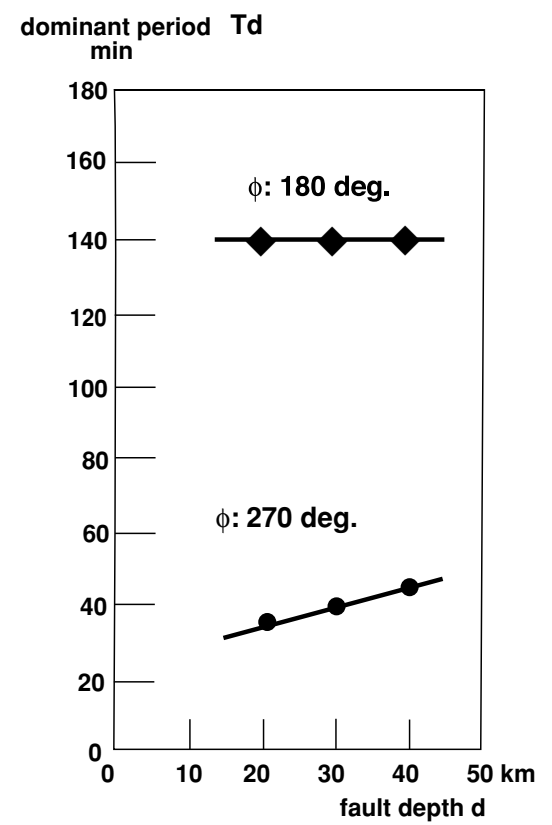

Fig. 9. Dependences of dominant period on fault depth $d$. Other fault parameters are fixed same as ones of the best one. 
of $139 \mathrm{~min}$ is $826 \mathrm{~km}$ for a sea depth of $1000 \mathrm{~m}$ in depth, which is $69 \%$ (approximately 2/3) of the fault length, 1200 $\mathrm{km}$. In the case of a tsunami consisting of one wave length corresponding to the fault length the period is equal to 202 minutes. In the normal direction of the fault wave length corresponding to the dominant period of 40 minutes for a sea depth of $1000 \mathrm{~m}$ is $238 \mathrm{~km}$ which is $216 \%$ (approximately 2.0$)$ of the width, $110 \mathrm{~km}$. Since wave length is approximated as $\lambda_{W}=2 W /((2 n+1) \cos \delta)$ in which $n$ is positive integer, the fundamental mode of fault width was excited and observed as the dominant period.

Lay et al. (2005) proposed a model consisting from three fault segments distributed along the island arc based on the rupture process. The total length reaches about $1300 \mathrm{~km}$ and the average rupture velocity of $2.5 \mathrm{~km} / \mathrm{s}$ was estimated. Our result is consitent with their result.

\section{Conclusion}

We studied dominant periods of the 2004 Sumatra tsunami from the spectra of tide gauge records. As a result dominant periods of 40 and 139 minutes were obtained in the normal direction and parallel direction of the fault, respectively. A theoretical approach was used to explain the relation between dominant period and fault size. The optimal source parameters obtained from this approach are a $1200 \mathrm{~km}$ fault length, a $110 \mathrm{~km}$ fault width and a sea depth of $1000 \mathrm{~m}$. The dominant period of 40 minutes is explained from the fundamental mode of fault width. This result does not conflict with a source region located on the continental slope.
Acknowledgments. We acknowledge those providing tide gauge records on homepage and the tsunami survey team visiting Indonesia for providing the tide gauge record at Sibolga. We also thank to Dr. Titov and anonymous reviewer for their constructive comments.

\section{References}

Abe, K., Tsunami resonance curve on dominant periods observed at bays, In Tsunamis: Case Studies and Recent Developments, Advances in Natural Technological Hazards Research, vol. 23, edited by K. Satake, 356 pp. Springer Publishers, 2005.

Fujima, K., Characteristics of Indian Ocean Tsunami in Maldive, Abst. Meeting of the Sumatra earthquake on 26 December 2004, 2005 (in Japanese).

Lay, T., H. Kanamori, C. J. Ammon, M. Nettles, S. N. Ward, R. C. Aster, S. L. Beck, S. L. Bilek, M. R. Bruzinski, R. Butler, H. R. DeShon, G. Ekstrom, K. Satake, and S. Sipkin, The great Sumatra-Andaman Earthquake of 26 December 2004, Science, 308, 1127-1133, 2005.

Satake, K., The 2004 Sumatra earthquake and tsunami in Indian Ocean: Seismological questions and future research, Abst. 2005 Japan Earth and Planet. Sci, Joint Meeting, 2005 (in Japanese).

Tsuji, Y., Y. Tanioka, Y. Nishimura, H. Matsutomi, T. Sakakiyama, T. Kamataki, Y. Murakami, Y. Namegaya, M. Matsuyama, M. Andrew, G. Guy, N. Sindhu, W. Budi, S. Inyoman, T. Rahmat, Alphonso, Yudhicara, Distribution of damage and heights of the tsunami of the 2004 Sumatra Earthquake in the city area of Banda Aceh and the vicinity, Abst. 2005 Japan Earth and Planet. Sci, Joint Meeting, 2005 (in Japanese).

Yamanaka, K., Source process of the 2004 Sumatra earthquake, Abst. 2005 Japan Earth and Planet. Sci, Joint Meeting, 2005 (in Japanese).

Yamashita, T. and R. Sato, Generation of tsunami by fault model, J. Phys. Earth, 22, 415-440, 1974.

K. Abe (e-mail: ABEKU@ngt.ndu.ac.jp) 